Mens

revue d'histoire intellectuelle de l'Amérique française

Caroline Désy. Si loin, si proche. La Guerre civile espagnole et le Québec des années trente. Québec, Presses de l'Université Laval, 2004. 177 p.

\title{
Magali Deleuze
}

Volume 6, numéro 2, printemps 2006

URI : https://id.erudit.org/iderudit/1024307ar

DOI : https://doi.org/10.7202/1024307ar

Aller au sommaire du numéro

Éditeur(s)

Centre de recherche en civilisation canadienne-française

ISSN

1492-8647 (imprimé)

1927-9299 (numérique)

Découvrir la revue

Citer ce compte rendu

Deleuze, M. (2006). Compte rendu de [Caroline Désy. Si loin, si proche. La

Guerre civile espagnole et le Québec des années trente. Québec, Presses de

l’Université Laval, 2004. 177 p.l Mens, 6(2), 272-278.

https://doi.org/10.7202/1024307ar 
guère. Il oublie que bien des néonationalistes, même s'ils s'en défendent, furent (et sont) aussi des néolibéraux.

Il importe de mentionner que l'auteur possède un sens certain de l'ironie dont on regrette, toutefois, la retenue. L'ouvrage en aurait bénéficié : le parfum de l'ironie favorise la dispersion des émanations de l'académisme.

En terminant, si certains se contentent de répéter au sujet de Lionel Groulx des platitudes immémoriales ou encore de " démontrer » l'existence du «non-sens » groulxien (ô paradoxe !), d'autres, comme Michel Bock, contribuent à éclairer la pensée d'un personnage qui reste, à bien des égards, un inconnu.

Patrick Dionne

Bibliothèque Albert-le-Grand

\section{Caroline Désy. Si loin, si proche. La Guerre civile espagnole et le Québec des années trente. Québec, Presses de l'Université Laval, 2004. 177 p.}

Dans cet ouvrage issu de sa thèse de doctorat soutenue en 1999, Caroline Désy s'attaque à l'histoire de la réaction des journaux montréalais à la guerre civile qui déchira l'Espagne de 1936 à 1939. L'auteure cherche principalement à faire ressortir le discours social sur la Guerre civile espagnole au Québec, ce qu'elle appelle le « discours dominant » et le « contre-discours ». L'ouvrage se situe dans la vague de renouveau de l'histoire des guerres et de l'histoire militaire qui connait, depuis une quinzaine d'années au Québec, une nouvelle jeunesse. Les historiens ne sont plus les seuls à s'y frotter; sociologues, politologues et professeurs de communication s'at- 
taquent, depuis quelques années, à un domaine jadis réservé à l'histoire : les sociétés et la guerre. Les études sur la Guerre civile espagnole et le Canada sont légion : Levinson en 1976, Gerassi en 1986, Howard en 1986, Beeching en 1989, Hannant en 1998, Parenteau en 1999, pour ne citer que les principales. La participation de plusieurs Canadiens sympathisants communistes à la guerre d'Espagne au sein du bataillon Mackenzie-Papineau ainsi que le départ pour l'Espagne en 1936 d'un chirurgien de Cartierville, Norman Bethune, décidé à soigner les blessés de la guerre, suscitent l'intérêt des historiens anglophones. Cependant, les études francophones sur le sujet et qui concernent plus particulièrement les Québécois et la guerre d'Espagne sont très rares, de même que les études sur la réaction des Québécois aux événements internationaux avant la Deuxième Guerre mondiale, d'où l'intérêt de ce livre.

Ce livre se divise en cinq chapitres suivis de quelques appendices. Le premier chapitre, "Contexte politique : danger et tentation ", permet à Caroline Désy de replacer le contexte des relations entre l'Église et l'État dans le Québec des années 1930, nœud des tensions qui traversent les idées de nationalisme, de fascisme et de corporatisme. Ces tensions aboutissent finalement à l'élection de Maurice Duplessis en 1936 et à un climat de répression où le danger communiste favorise un discours social de la menace : menace génératrice d'identité, menace culturelle française, menace de l'américanisation.

Le deuxième chapitre est consacré à l'analyse du discours dominant qui émane principalement des ecclésiastiques québécois et de la position du pape Pie XI sur la guerre d'Espagne qui est présentée comme «l'ultime combat de la civilisation chrétienne contre la barbarie communiste » (p. 21). Les tenants du discours dominant ont fort à faire en 1937 pour 
convaincre les Québécois que les réfugiés espagnols qui commencent à arriver à Montréal ont fui l'Enfer et Satan. Le $\mathrm{D}^{\mathrm{r}}$ Norman Bethune fait une tournée canadienne et québécoise en 1937 pour dénoncer l'ignominie de la guerre et les pratiques fascistes des troupes franquistes en Espagne et plusieurs intellectuels français, dont André Malraux, n'hésitent pas à s'engager aux côtés des communistes espagnols. Le Devoir, La Presse, La Patrie et L'Action nationale font une large place au discours dominant bâti autour de la condamnation du gouvernement du Front populaire espagnol antireligieux et antisocial, de la notion de guerre juste contre les communistes en Espagne, de la polarisation rouge-blanc et de la nécessaire résistance d'une civilisation chrétienne contre la barbarie communiste. Ce discours, ecclésiastique mais aussi politique, amène inévitablement à la sacralisation de la guerre d'Espagne dans ces journaux québécois.

Le troisième chapitre rappelle un certain nombre d'événements qui ont piqué l'intérêt de plusieurs Québécois. Le rédacteur en chef du journal Le Canada lance le bal dans une critique cinglante du fascisme espagnol dans un éditorial, en août 1936, donnant lieu à de nombreuses réactions médiatiques. Les esprits s'échauffent encore, en octobre 1936, lorsqu'une délégation de républicains espagnols vient faire une tournée aux États-Unis et au Canada. Le père Sarasola, un prêtre espagnol, en fait partie, ce qui déclenche l'ire des tenants du discours dominant et de l'ensemble des journaux qui tentent de discréditer la délégation antifasciste. Le passage d'André Malraux au Québec, fervent défenseur du Front populaire espagnol et militant communiste, donne lieu à plusieurs polémiques où la catégorisation et le stéréotype sont largement utilisés dans les médias de la «droite » québécoise.

Les chapitres quatre et cing font le point sur la recherche d'un contre-discours, condamnant le fascisme espagnol 
et critiquant, comme Laurendeau, le fait que «Nous sommes trop souvent de ceux qui pensent, suivant la dure formule de la Vie intellectuelle, que Dieu est à droite» (p. 77)... Discours marginal que l'on retrouve dans Le Canada, Le Jour et Clarté qui tous ensemble ne constituent qu'un tiers du tirage de $L a$ Presse, mais qui révèle notamment la force de l'idée pacifiste qui sera reprise au Québec lors d'autres événements ultérieurs. La position des journaux anglophones, The Montreal Daily Star et The Gazette, oscille entre une relative neutralité et une critique des groupes extrémistes, fascistes ou communistes. Ces journaux s'alignent sur la politique britannique vis-à-vis de la Guerre civile espagnole : neutralité et non-intervention pour ne pas déstabiliser le fragile équilibre européen.

Le sujet abordé dans ce livre est ambitieux et passionnant. Le défi est donc grand pour l'auteure de parvenir à cerner, analyser et évaluer la réaction de certains Québécois à la Guerre civile espagnole. Le titre est trompeur. Il ne s'agit pas ici, malheureusement, de l'étude de la réaction du "Québec » à la Guerre civile espagnole, mais de journalistes et de quelques intellectuels québécois qui se sont exprimés dans huit journaux et trois revues. Il s'agit donc plutôt d'une étude sur les médias ou sur la réaction dans les médias à la Guerre civile espagnole. La thèse de Caroline Désy s'intitulait Discours bégémonique et contre-discours sur la guerre d'Espagne dans le Québec des années trente, ce qui était beaucoup plus honnête. Les maisons d'éditions sont les grandes responsables de ce "travestissement » des titres qui dessert plus qu'il ne sert les auteurs et déçoit le lecteur qui ne trouve pas dans le livre ce qu'on lui annonce dans le titre. L'auteure apporte, dans ce livre, un éclairage sociologique sur la question et tente de «cerner le discours social sur la Guerre civile espagnole au Québec, particulièrement dans les journaux montréalais » (p. 4). 
L'introduction et le premier chapitre sur le contexte laissent le lecteur sur sa faim. On retrouve beaucoup d'approximations sur l'historiographie de la période. Parler du "Québec des années trente, longtemps recouvert du rideau mythique de la grande noirceur, donc destiné à l'oubli» (p. xiv) montre une méconnaissance des dernières études historiques sur cette période (études sur le syndicalisme, sur les partis politiques, sur les femmes, sur les idéologies, etc.). Quant au "rideau mythique » de la grande noirceur, on en a défilé depuis longtemps toutes ses mailles.... Les titres consultés par l'auteure comportent des lacunes gênantes pour l'historien. Il n'est fait aucune mention des articles et études de Pierre Trépanier sur les droites québécoises des années trente et sur Lionel Groulx, ni des thèses de Michel Bock et de Norman F. Cornett sur Lionel Groulx, ni de la demi-douzaine de maitrises et de doctorats d'histoire sur les idéologies des années trente (Pascale Ryan, Yves Bégin, etc.). On comprend parfaitement que les études sociologiques soient privilégiées dans ce livre, mais lorsque la sociologie se fait historique, elle doit aussi se baser sur les dernières recherches historiques. L'américanisation, dans le Québec des années trente, est aussi abordée dans la présentation contextuelle de l'auteure, mais on a bien du mal à comprendre le lien avec la Guerre civile espagnole et on s'attendait à ce que l'auteure explore ou situe son travail par rapport aux théories de Gérard Bouchard sur l'américanité. Pourtant l'allusion que fait l'auteure au lien entre libéralisme économique et développement du communisme pique la curiosité et mériterait une analyse plus profonde.

Ces réserves apportées, on entame avec intérêt la lecture de l'analyse que fait l'auteure du discours sur la guerre d'Espagne. L'analyse des éléments du discours dominant de la majorité des journaux et revues du Québec, qui condamnent au fond un régime espagnol communiste et athée, fait 
bien ressortir l'universalisme de la pensée catholique et le fait que la sacralisation du conflit se retrouve aussi bien en France qu'au Québec. Les abbés Henri Jasmin et Camille Poisson sont particulièrement virulents contre le caractère antichrétien de la guerre d'Espagne et condamnent tout soutien à la république espagnole ou au Front populaire, même si ce soutien émane de catholiques "nouveau genre " comme François Mauriac ou Jacques Maritain. La présentation des temps forts du discours dominant lors de plusieurs événements qui ont particulièrement intéressé les journalistes québécois ouvre de nombreuses pistes de réflexion. On réalise, notamment, que ce discours était parfois sévèrement critiqué par des journalistes et des intellectuels et que dominant ne veut pas dire unique. La richesse des éditoriaux et du contenu des articles constituant le corpus de ce chapitre représente un des temps forts de ce livre et chaque thème retenu aurait pu, sans problème, faire l'objet d'un chapitre complet.

Il aurait été fort intéressant de connaitre la position de Lionel Groulx sur la guerre d'Espagne. L'auteure explore avec aisance le contre-discours face à la guerre d'Espagne, bien que l'on s'étonne du titre de ce chapitre, «À la recherche d'un contre-discours » (p. 69), car enfin il en existe bien un, et ce dès le début de la guerre d'Espagne. On retrouve ici une diversité de points de vue qui caractérise la vie intellectuelle canadienne-française et qui renvoie à leurs stylos ceux qui tentent de nous persuader de l'uniformité dans les discours intellectuels au Québec ou, pire, dans l'opinion publique québécoise. Par ailleurs, les tenants de la condamnation du fascisme espagnol viennent de divers horizons : des catholiques (André Laurendeau pour un temps, la revue La Relève), des journalistes (dans Le Canada, Jean-Charles Harvey du Jour), etc. Leur discours ne sacralise pas le conflit, mais le présente comme un conflit politique opposant fascistes et républicains. 
On aurait aimé trouver ici une analyse de l'évolution chronologique du discours. N'y a-t-il pas une évolution dans les discours face à la guerre d'Espagne qui tient compte de la transformation à la fois du conflit mais aussi de la situation au Québec? On retrouve d'ailleurs cette périodicité dans la partie consacrée aux journaux anglophones. Pourquoi ne pas avoir placé la réaction des journaux anglophones dans le contrediscours ? Ils rejoignent, par leur grille d'analyse politique de la guerre d'Espagne, par leur condamnation tantôt du fascisme tantôt du communisme et par leur soutien à la démocratie, les arguments principaux de ce que l'auteure appelle le contrediscours. Il serait intéressant également de se livrer à une étude quantitative (indices de mise en forme et de mise en valeur) afin de pouvoir comparer l'impact réel de la Guerre civile espagnole au Québec par rapport à d'autres événements étrangers dans les journaux québécois. Ce livre de Caroline Désy fait naître bien des idées, et même s'il ne répond pas à toutes les interrogations historiques, il a le mérite d'ouvrir la voie pour d'autres études tout en nous éclairant sur une partie de l'analyse sociologique du discours au Québec.

Magali Deleuze

Département d'bistoire Collège militaire royal du Canada 